\title{
Synthesis, Characterization and Curing Studies of Thermosetting Epoxy Resin with Amines
}

\author{
Lakshmi. B, Shivananda. K. N, ${ }^{\dagger}{ }^{*}$ and Mahendra. K. $\mathbf{N}^{*}$ \\ Department of Studies in Chemistry, Central College Campus, Bangalore University, Bangalore-560001 \\ ${ }^{\dagger}$ Schulich Faculty of Chemistry, Technion - Israel Institute of Technology, Technion City, Haifa -32000, Israel \\ *E-mail: shivananda_kn@yahoo.com \\ Received October 21, 2009, Accepted June 21, 2010
}

\begin{abstract}
A new hybrid thermosetting maleimido epoxy compound 4-( $N$-maleimidophenyl) glycidylether (N-MPGE) is prepared by reacting $N$-(4-hydroxyphenyl) maleimide (HPM) with Epichlorohydrin by using benzyltrimethylammonium chloride as a catalyst. The resulting compound possesses both the oxirane ring and maleimide group. The curing reaction of these maleimidophenyl glycidylether epoxy compound (N-MPGE) with amines as curing agents such as ethylendiamine (EDA), diethylentriamine (DETA) and triethylenetetramine (TETA), aminoethylpiperazine (AEP) and isophoronediamine, IPDA), are studied. Incorporation of maleimide groups in the epichlorohydrin provides cyclic imide structure and high cross-linking density to the cured resins. The cured samples exhibited good thermal stability, excellent chemical (acid/alkali/solvent) and water absorption resistance. Morphological studies by the SEM technique further confirmed the phase homogeneity net work of the cured systems.
\end{abstract}

Key Words: Amine, Epoxy resin, Malemide, Curing, Epichlorohydrin

\section{Introduction}

Epoxy resins are widely used in industrial applications owing to their many attractive properties, such as excellent chemical and solvent resistance, good thermal and electrical properties. Other major applications of epoxy resins include the manufacture of printed circuit boards, composites, tooling and casting, adhesives and putties. Civil engineering uses of epoxy resins include flooring, crack injection, grouts, sealants, paving and concrete flooring. Epoxies can be employed in two-pack, ambient cured maintenance coatings. In many applications amines, anhydrides, fatty acids, acrylics, polyesters, polyisocyanides and amides are used as curing agents to study the effect on the curing rate and related properties. ${ }^{1}$

At present epoxy resins are extensively used in technical applications such as coatings, composites and as structural adhesives. $^{2}$ Use of epoxy resins in high performance structural material is getting more and more popular. There is a lot of scope and need for improving the properties of epoxy resins to be used in advanced applications. For example, epoxy resin with superior thermal stability is needed for using as molding compounds and encapsulation materials in advanced electronic components. Generally, modifying epoxy resin with polyamides or imido compounds ${ }^{2-3}$ provides a convenient approach of enhancing the thermal stability of epoxy resins. Therefore, epoxy resins were cured with reactive polyimides, ${ }^{2-4}$ polyamic acid, ${ }^{5}$ and imidomodified curing agents ${ }^{6}$ to introduce imide structure into epoxy resin. The thermal stability of the above mentioned imido epoxy resins was significantly leveled up both in the initial decomposition temperature (IDT) and the integral procedural decomposition temperature (IPDT).

On the other hand, epoxy resins modified with maleimide compounds also received attractive attentions, due to the similar curing conditions and processing properties of the epoxy resins and maleimides. Maleimide-epoxy resins usually showed appropriate properties between epoxy and maleimide resins. Thus, both the intercrossed and the interpenetrating systems (IPN) based on bismaleimides and epoxy resins were prepared which exhibited good thermal and mechanical properties Additionally, since imide groups could provide char formation in the condensed phase to improve polymers flame retardant properties, epoxy resins modified with imide compounds through chemical reactions or physical blending have been reported to show good flame retardant properties. . $^{8}$

In this paper we first synthesize a maleimide compound with a hydroxyl group. We obtain maleimidophenyl glycidylether epoxy compounds through a simple addition reaction between the oxirane group of epichlorohydrin and hydroxyl group of the maleimide. The resulting maleimidophenyl glycidylether epoxy compound possessed (possesses) both oxirane ring and maleimide reactive groups. Each of the reactive groups might form cross-mlinking networks under thermal curing reaction with curing agents to bring about high cross-linking density. So it is considered worthwhile to study the synthesis, characterization and curing reaction of the maleimidophenyl glycidylether epoxy compounds with different amines and to study properties of the cured resin systems. The cured samples are found to have good thermal stability, chemical resistance and water absorption resistance. The cured samples exhibited homogeneity with no phase separation which was confirmed by scanning electron microscopy (SEM).

\section{Experimental Section}

Materials. Maleic anhydride and 4-aminophenol were purchased from S.d.Fine chemicals. The following amines were used. Ethylenediaine (EDA), diethylenetriamine (DETA), triethylenetetramine (TETA), 1-(2-aminoethyl) piperazine (AEP) 
and 5-amino-1,3,3-trimethylcyclohexanemethylamine (isophoronediamine, IPDA), and benzyltrimethyl ammonium chloride (BTAC) were supplied by Aldrich Chemicals. Dimethylformamide (DMF), $p$-toluenesulphonic acid, toluene, sodium bicarbonate, ethyl acetate, $\mathrm{H}_{2} \mathrm{SO}_{4}, \mathrm{HNO}_{3}, \mathrm{HCl}, \mathrm{C}_{6} \mathrm{H}_{6}, \mathrm{CH}_{3} \mathrm{CH}_{2} \mathrm{OH}$, $\mathrm{NH}_{3}$ and $\mathrm{NaOH}$ were obtained from Merck Chemicals. Infrared spectra were recorded using Nicolet FT-IR spectrometer using $\mathrm{KBr}$. Elemental analyses were carried out in Liquid Crystal Department, Raman Research Institute, Bangalore. The ${ }^{1} \mathrm{H}$ NMR spectra of MIE compound is recorded in Sophisticated Instrument Facility, Indian Institute of Science, Bangalore. TGA and DSC for cured samples is recorded in National Chemical Laboratory, Pune.

Synthesis of $\mathrm{N}$-(4-hydroxyphenyl) maleimide (HPM). Experimental procedure for the synthesis and characterization of HPM is the same as given in previous works ${ }^{21,22}$ by the authors.

Synthesis of 4-( $\mathrm{N}$-maleimidophenyl) glycidylether (N-MPGE). HPM (0.1 mol, $18.7 \mathrm{~g})$ was mixed with $100 \mathrm{~g}$ of epichlorohydrin $(\mathrm{ECH})$ in a $500 \mathrm{~mL} 3$-necked flask equipped with a stirrer, condenser, and a nitrogen inlet. After adding BTAC (1.8 $\mathrm{g}, 0.01 \mathrm{~mol}$ ) to the solution, the mixture was stirred under nitrogen for $24 \mathrm{~h}$ at $60^{\circ} \mathrm{C}$. Excess ECH was removed under reduced pressure and the solid residue was dissolved in ethyl acetate, washed with water and dried over $\mathrm{MgSO}_{4}$. The product was purified by chromatography using a silica column and ethyl acetate/ toluene ( $1: 1$ in vol.) to give MPGE product (yield 55\%; melting point, $45-50{ }^{\circ} \mathrm{C}$; epoxy equivalent weight $\left.=254\right)$. IR $(\mathrm{KBr}$, $\left.\mathrm{cm}^{-1}\right) 715$ (C=O bending), 912 (oxirane-ring), 1248, 1037 (Ph$\left.\mathrm{O}-\mathrm{CH}_{2}\right), 1375(\mathrm{C}-\mathrm{N}$ stretching), $1609(\mathrm{C}=\mathrm{C}), 1715(\mathrm{C}=\mathrm{O}$ symmetric stretching), $1781(\mathrm{C}=\mathrm{O}$ asymmetric stretching $), 3070(\mathrm{C}$ $\mathrm{H}$ of imide group). ${ }^{1} \mathrm{H}$ NMR (300 MHz, DMSO- $\left.d_{6}, \mathrm{ppm}\right) 2.72$ and $2.87\left(2 \mathrm{H},-(\mathrm{O}) \mathrm{CH}_{2}\right) ; 3.68\left({ }^{1} \mathrm{H},-\mathrm{CH}_{2} \mathrm{CH}(\mathrm{O})-\right)$; 4.13-4.26 $(2 \mathrm{H}$, $\left.-\mathrm{Ph}-\mathrm{OCH}_{2}-\right)$; 6.87 (2H, $\left.-\mathrm{CH}=\mathrm{CH}-\right)$; 7.03-7.54 (4H, aromatic protons).
Preparation of cured epoxy resins. The cured epoxy resins were obtained by thermally curing of epoxy resin (N-MPGE) with amines such as ethylenediamine (EDA), diethylenetriamine (DETA)triethylenetetramine (TETA),1-(2-aminoethyl) piperazine (AEP) and 5-amino-1,3,3-trimethyl cyclohexanemethylamine (isophoronediamine, IPDA) as curing agents. Epoxy resin (N-MPGE) and the amines were dissolved in methylethylketone to form a homogeneous solution. After evaporating the solvent at ambient temperature the mixture was cured with specific curing condition to result in cured resins. The curing conditions are listed in Table 1.

Moisture absorption and chemical resistance measurements. Water absorption and chemical resistance tests are conducted as explained in the previous works by the authors. ${ }^{21,22}$ The chemical resistance tests were carried out in acetone $\mathrm{H}_{2} \mathrm{SO}_{4}, \mathrm{HNO}_{3}$, $\mathrm{HCl}, \mathrm{C}_{6} \mathrm{H}_{6}, \mathrm{CH}_{3} \mathrm{CH}_{2} \mathrm{OH}, \mathrm{NH}_{3}$ and $\mathrm{NaOH}$ solutions. We use same thickness samples for the tests. An average of three sample readings is recorded at room temperature.

\section{Results and Discussions}

Preparation of N-MPGE epoxy compound. 4-( $\mathrm{N}$-Maleimidophenyl) glycidylether (N-MPGE) was prepared from reacting epichlorohydrin with $N$-(4-hydroxyphenyl)maleimide (HPM) which was synthesized. according to Scheme 1 . The first attempt of synthesizing N-MPGE was performed under basic conditions by employing $\mathrm{KOH}$ as a catalyst. The crude product was analyzed with thin layer chromatography which showed complicated compositions containing various by products. The pure N-MPGE was obtained by means of column chromatography with a low yield of less than $25 \%$. The strong basic condition of the reaction might cause the hydrolysis of the imide groups of HPM and N-MPGE, therefore, to result in mixed by products. To compensate for this flaw, benzyltrimethyl ammonium chlo-

Table 1. Preparation and curing conditions and thermal stability of cured systems evalution with TGA and DSC under air atmosphere

\begin{tabular}{|c|c|c|c|c|c|c|}
\hline \multirow{2}{*}{ Sl. No } & \multirow{2}{*}{ System } & \multirow{2}{*}{ Curing conditions } & \multicolumn{2}{|c|}{ Thermal stability } & \multicolumn{2}{|c|}{ DSC data } \\
\hline & & & $\mathrm{IDT}^{\circ} \mathrm{C}$ & $\operatorname{IPDT}^{\circ} \mathrm{C}$ & $\mathrm{T}_{\text {endo }}{ }^{\circ} \mathrm{C}$ & $\mathrm{T}_{\text {exo }}{ }^{\circ} \mathrm{C}$ \\
\hline 1 & N-MPGE + EDA & $125^{\circ} \mathrm{C}(1 \mathrm{~h}), 170{ }^{\circ} \mathrm{C}(2 \mathrm{~h})$ & 400 & 450 & 75 & 330 \\
\hline 2 & N-MPGE + DETA & $125^{\circ} \mathrm{C}(1 \mathrm{~h}), 170{ }^{\circ} \mathrm{C}(2 \mathrm{~h})$ & 402 & 455 & 77 & 340 \\
\hline 3 & N-MPGE + TETA & $125^{\circ} \mathrm{C}(1 \mathrm{~h}), 170{ }^{\circ} \mathrm{C}(2 \mathrm{~h})$ & 406 & 458 & 78 & 365 \\
\hline 4 & N-MPGE + AEP & $125^{\circ} \mathrm{C}(1 \mathrm{~h}), 170{ }^{\circ} \mathrm{C}(2 \mathrm{~h})$ & 410 & 467 & 80 & 369 \\
\hline 5 & N-MPGE + IPDA & $125^{\circ} \mathrm{C}(1 \mathrm{~h}), 170{ }^{\circ} \mathrm{C}(2 \mathrm{~h})$ & 402 & 455 & 75 & 360 \\
\hline
\end{tabular}
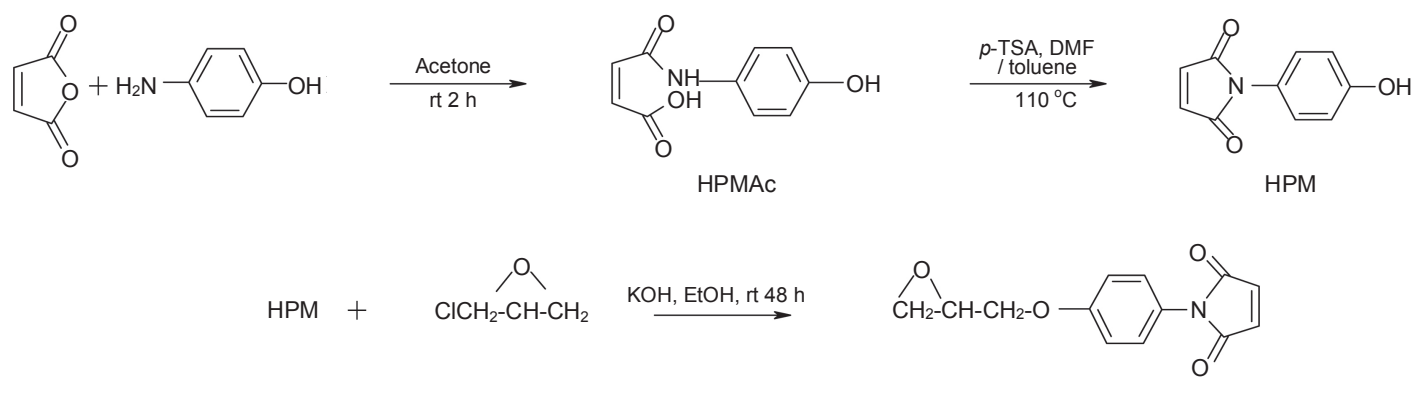

Scheme 1. Preparation of $N$-maleimidophenyl glycidyl ether of epoxy compound 


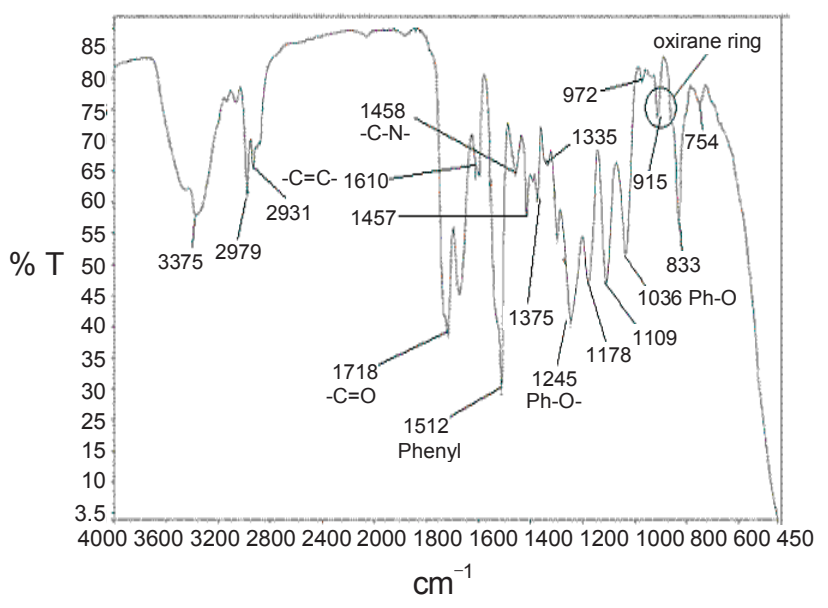

Figure 1. FT-IR spectrum of 4-( $N$-maleimidophenylglycidylether).

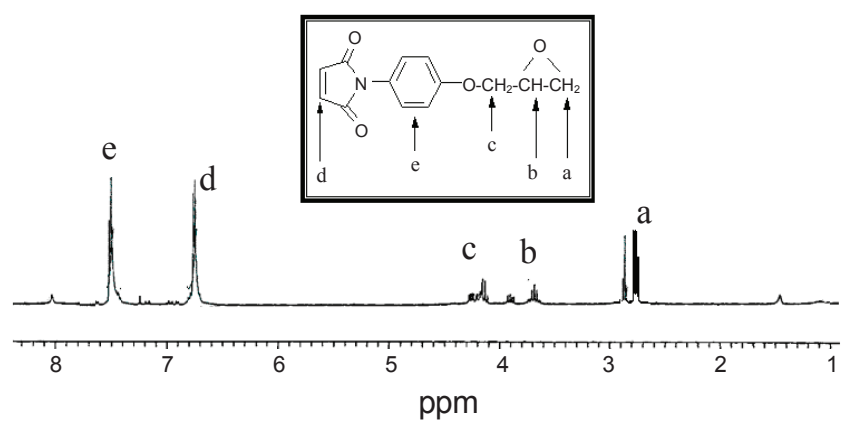

Figure 2. ${ }^{1} \mathrm{H}$ NMR spectrum of MPGE.

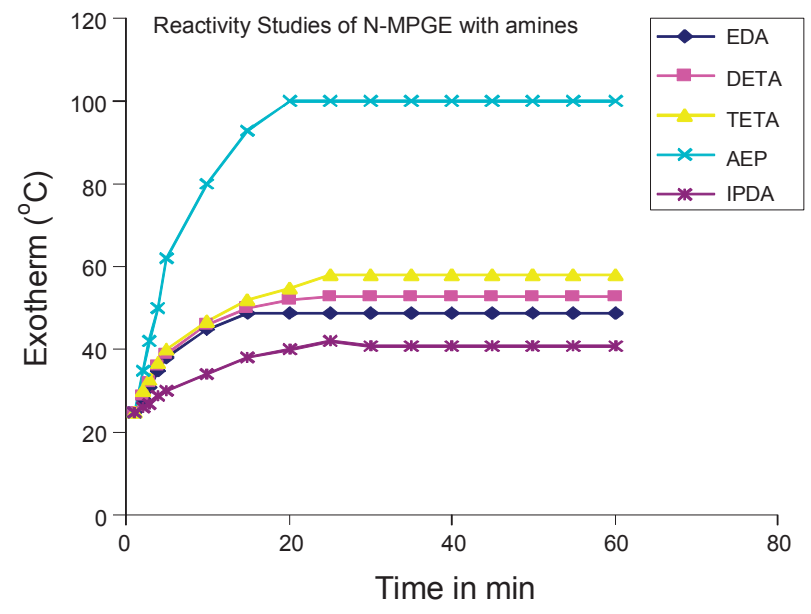

Figure 3. Reactivity studies of $N$-maleimidophenylglycidyl ether of resin with amines at room temperature.

ride (BTAC), which was reported being useful in the synthesis of glycidyl phosphinate compounds without causing hydrolysis of the phosphinate compounds, ${ }^{21-27}$ was utilized in the synthesis of N-MPGE. The product yield was significantly raised by about $75 \%$. The chemical structure of N-MPGE compound was assigned on the basis of FT-IR, elemental analysis and ${ }^{1} \mathrm{H}$ NMR studies. The absorption peak at around $915 \mathrm{~cm}^{-1}$ which was observed in the FT-IR spectrum of N-MPGE (Figure 1) demon-
Table 2. Reactivity studies data of $N$-maleimidophenylglycidyl ether of epoxy compound with amines

\begin{tabular}{llcccr}
\hline $\begin{array}{l}\text { Sl. } \\
\text { No }\end{array}$ & \multicolumn{1}{c}{ System } & $\begin{array}{c}\text { Wight of } \\
\text { N-MPGE } \\
(\mathrm{g})\end{array}$ & $\begin{array}{c}\text { Weight } \\
\text { of amine } \\
(\mathrm{g})\end{array}$ & $\begin{array}{c}\text { Curing } \\
\text { Time in } \\
\text { min }\end{array}$ & $\begin{array}{c}\text { Exotherm } \\
\left({ }^{\circ} \mathrm{C}\right)\end{array}$ \\
\hline 1 & N-MPGE + EDA & 10 & 0.35 & $50 \pm 1$ & $49 \pm 0.2$ \\
2 & N-MPGE + DETA & 10 & 0.64 & $45 \pm 1$ & $53 \pm 0.3$ \\
3 & N-MPGE + TETA & 10 & 0.76 & $38 \pm 1$ & $58 \pm 0.4$ \\
4 & N-MPGE + AEP & 10 & 1.20 & $15 \pm 1$ & $100 \pm 0.6$ \\
5 & N-MPGE + IPDA & 10 & 1.25 & $65 \pm 1$ & $41 \pm 0.1$ \\
\hline
\end{tabular}

strates the formation of oxirane groups. The absorption peaks deriving from the cyclic maleimide group were also observed at $1781(\mathrm{C}=\mathrm{O}$ asymmetric stretching $), 1718(\mathrm{C}=\mathrm{O}$ symmetric stretching), and 1375 (C-N stretching), and $1610(\mathrm{C}=\mathrm{C}) \mathrm{cm}^{-1}$. Other specific absorption bands at $3070(\mathrm{C}=\mathrm{C}-\mathrm{H}), 1245,1037$ ( $\mathrm{Ph}-\mathrm{O}-\mathrm{CH}_{2}$ ), and $1513 \mathrm{~cm}^{-1}$ (phenyl) gave more evidence to the obtained compound having the expected chemical structure. Further characterization was performed with ${ }^{1} \mathrm{H}$ NMR analysis on the MIE compound which also indicated the proposed chemical structure as shown in the Scheme 1 (Figure 2). The ${ }^{1} \mathrm{H}$ NMR signals observed are assigned as below; $2.888 \mathrm{ppm}$ and $2.678 \mathrm{ppm}\left(2 \mathrm{H},-(\mathrm{O}) \mathrm{CH}_{2}\right) ; 3.238 \mathrm{ppm}\left(1 \mathrm{H},-\mathrm{CH}_{2} \mathrm{CH}(\mathrm{O})-\right) ; 3.575$ ppm ( $\left(2 \mathrm{H},-\mathrm{Ph}-\mathrm{OCH}_{2}-\right) ; 6.87 \mathrm{ppm}(2 \mathrm{H},-\mathrm{CH}=\mathrm{CH}-)$; and $7.03-7.54$ ppm ( $4 \mathrm{H}$, aromatic protons). The chemical shifts of the absorption peaks and the area ratios of the peak integration were found to be consistent with the expected chemical structure. Moreover, the experimental results of titration of epoxy equivalent weight also demonstrated the successful of synthesis of N-MPGE compound. N-MPGE is soluble in most of the industrially solvents, such as acetone, methylethylketone, tetrahydrofuran, $\mathrm{N}, \mathrm{N}$-dimethylacetamide, dimethylsulfoxide, ethyl acetate, methanol, ethanol, 1-methyl-2-pyrrolidone and dimethylformamide. The good organo-solubility of N-MPGE suggests its good processibility associat with the current industrial processes.

Curing reactions of N-MPGE with amines. The curing reaction between N-MPGE with amines is carried out with different amines such as EDA, DETA, TETA, AEP and IPDA based on their hydrogen equivalent weights. N-MPGE resin was taken on an aluminum foil of about $10 \mathrm{~cm}$ diameter and the amine was added and mixed thoroughly for a minute using a thin wooden stick. In all the cases, the temperature of the reaction mixture at different intervals of time was measured using an infrared gun and the completion of the curing process is indicated when the reaction mixture became non-sticky to the wooden stick. The average of the three ridings is listed in Table 2.

The epoxide groups in the resin react with the amine to form a highly cross linked, three dimensional network. The curing process converts the epoxy resin into a hard, infusible and rigid material. All the curing reactions were carried out at room temperature $\left(26^{\circ} \mathrm{C}\right)$. The mechanism of curing reaction is given in Scheme 2.

The reactivity data (see Table 2 and Figure 3 ) clearly indicates that the reactivity trend increases in the order AEP $>$ TETA $>$ DETA $>$ EDA $>$ IPDA. The reactivity mainly depends on the nature of amino groups present in the curing agents. Ethylenediamine has only primary amine group whereas diethylene- 

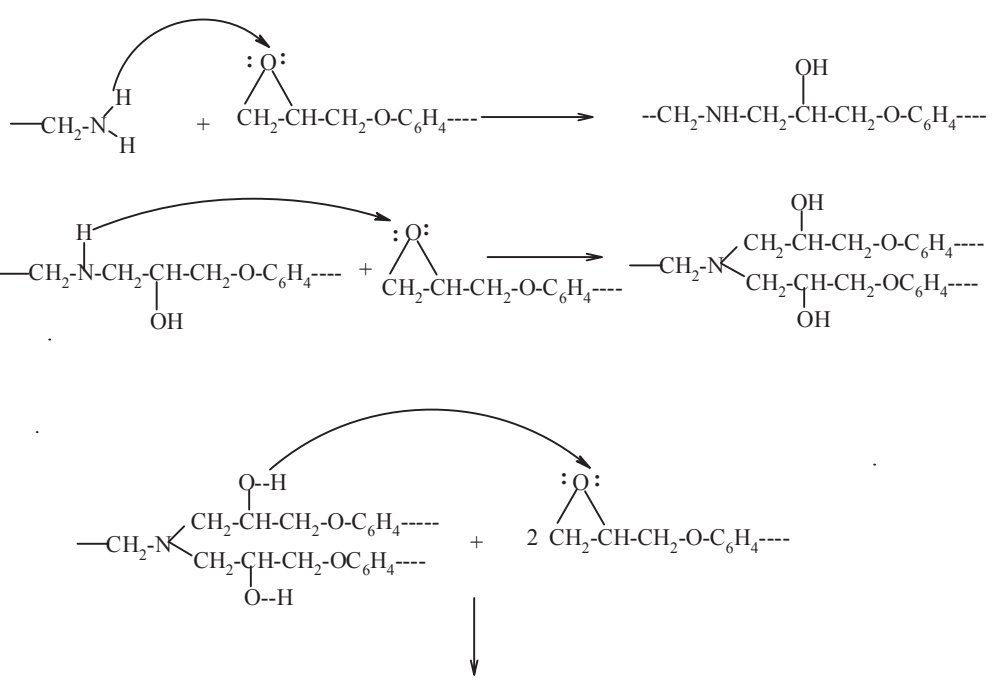

$$
\begin{gathered}
\mathrm{OH} \\
\mathrm{O}-\mathrm{CH}_{2}-\mathrm{CH}-\mathrm{CH}_{2}-\mathrm{O}-\mathrm{C}_{6} \mathrm{H}_{4}--- \\
-\mathrm{CH}_{2}-\mathrm{K}^{\mathrm{K}_{2}-\mathrm{CH}_{-}-\mathrm{CH}_{2}-\mathrm{O}-\mathrm{C}_{6} \mathrm{H}_{4}----} \\
\mathrm{CH}_{2}-\mathrm{CH}-\mathrm{CH}_{2}-\mathrm{O}-\mathrm{C}_{6} \mathrm{H}_{4}^{----} \\
\mathrm{O}-\mathrm{CH}_{2}-\mathrm{CH}_{-}-\mathrm{CH}_{2}-\mathrm{O}-\mathrm{C}_{6} \mathrm{H}_{4}---- \\
\mathrm{OH}
\end{gathered}
$$

Scheme 2. The reaction mechanism of amine with oxirane ring

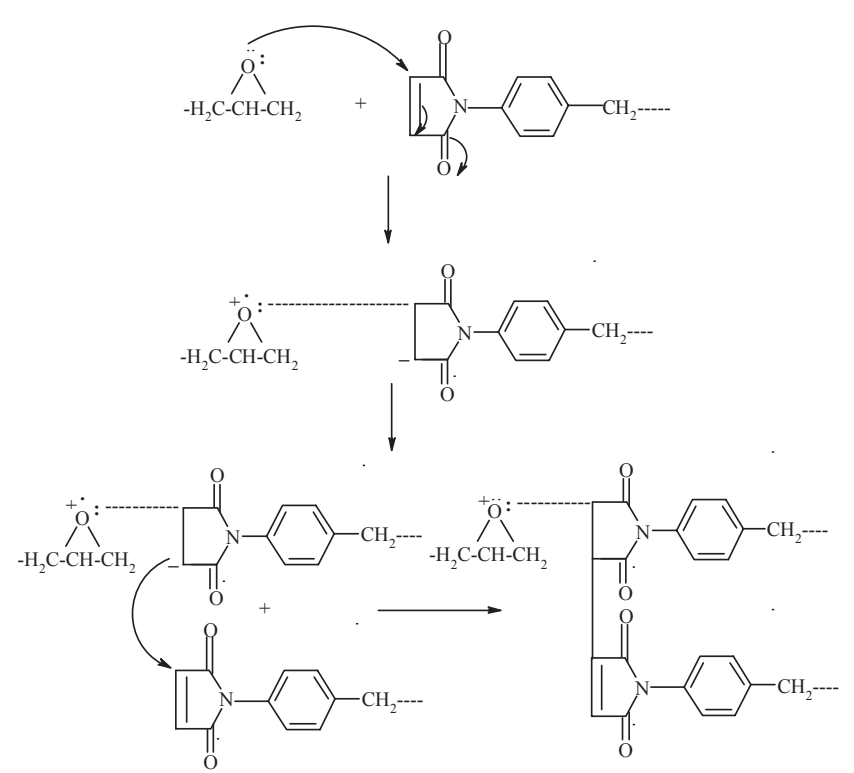

Scheme 3. Self-addition reaction of maleimide groups of N-MPGE compound

triamine and triethylentetramine have both primary and secondary amine groups. In the case of aminoethylpiperazine, the increase in reactivity may be explained due to the cumulative effects of primary, secondary and tertiary amino groups present. The slow reactivity in the case of isophoronediamine may be because of its alicyclic character even though it has a primary amino group. The resin is cross linked by reactive molecules which link across the epoxy units and become part of the structure.

These data clearly indicate that the cured N-MPGE with the curing agents (EDA, DETA, TETA, AEP, and IPDA) showed that the AEP is more reactive when compared to the other

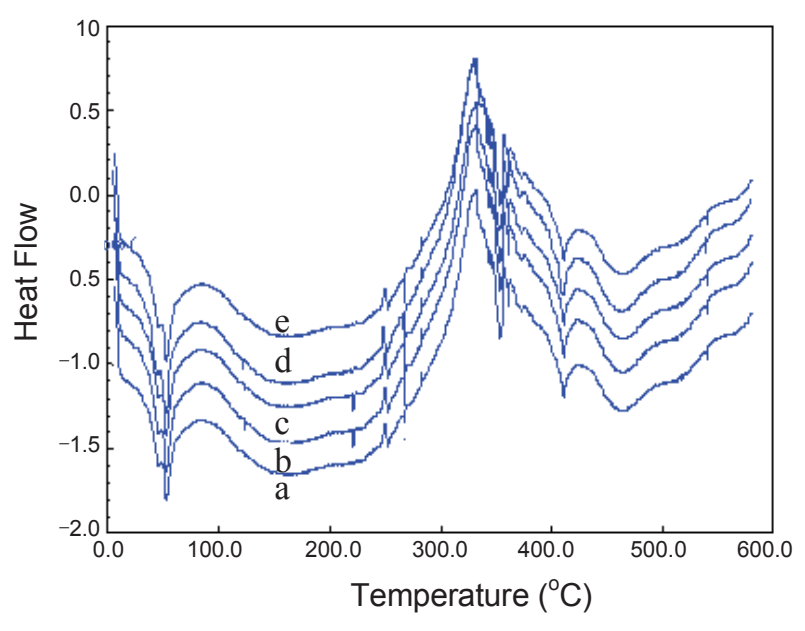

Figure 4. Dynamic DSC thermograms of the five systems a) N-MPGE + EDA, b) N-MPGE + DETA, c) N-MPGE + TETA. d) N-MPGE + AEP and e) N-MPGE + IPDA.

amines. ${ }^{23}$ This can be possibly credited to the presence of tertiary nitrogen atom in AEP (acts as catalyst), which accelerates the curing rate to a very high value as compared to other amines amines. $^{21-24}$

It is also well known that both the oxirane group and maleimide group react with amine groups through self addition reactions (Scheme 3). Moreover, the maleimide groups might crosslink through self-addition reaction under heating. ${ }^{19}$ Therefore, while curing N-MPGE with curing agents, all the three abovementioned reactions might occur. In this work, the curing compositions were taken with the same stoichiometric amounts of the amine curing agent and oxirane groups. Therefore, most of the amine groups are expected to react with oxirane groups at low temperature region. Since almost no amino group was left 


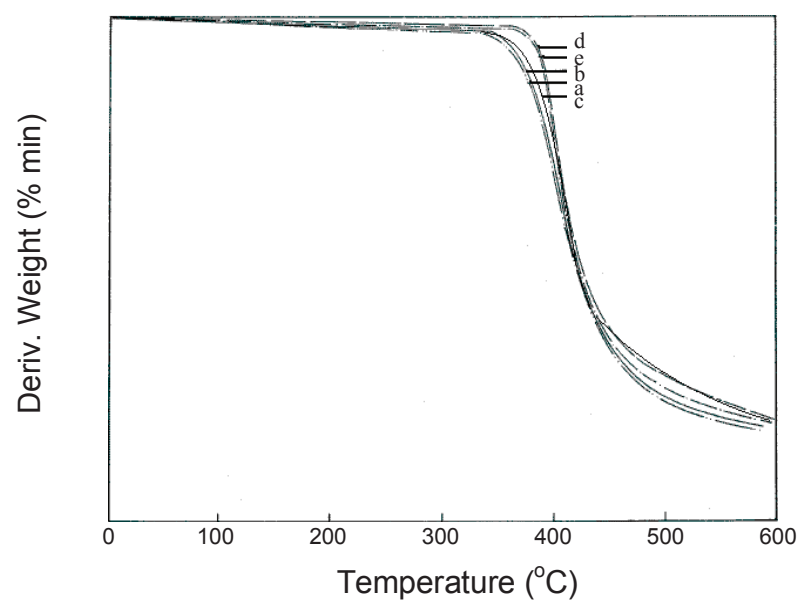

Figure 5. Thermogravimetric analysis (TGA) a) N-MPGE + EDA, b) N-MPGE + DETA, c) N-MPGE + TETA. d) N-MPGE + AEP and e) N-MPGE + IPDA.

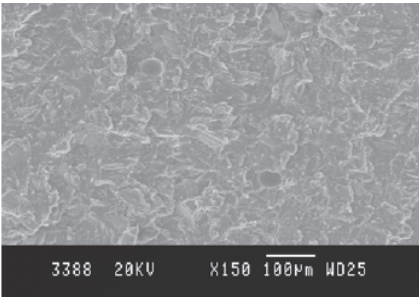

(a) N-MPGE + EDA

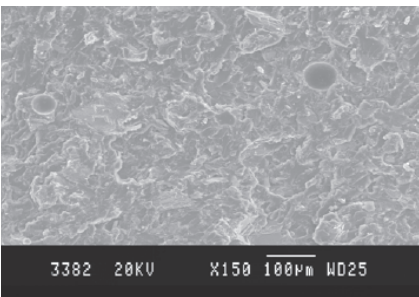

(c) N-MPGE + TETA

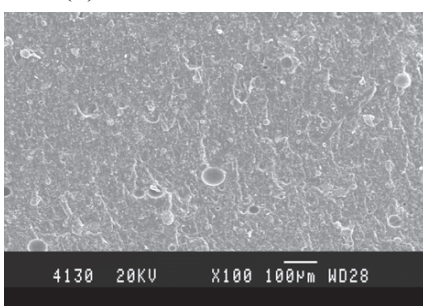

(e) N-MPGE + IPDA

Figure 6. Fractured morphology analysis of cured maleimidophenyl glycidylether with different amines. a) N-MPGE + EDA, b) N-MPGE + DETA, c) N-MPGE + TETA, d) N-MPGE + AEP and e) N-MPGE + IPDA.

to react with maleimide group, only self-addition reaction occurred for maleimido groups in the curing reaction. The resulting products obtained were therefore supposed to have high cross linking densities.

Differential scanning calorimetric (DSC) studies of cured systems. Dynamic DSC thermograms of the five systems (NMPGE + EDA, N-MPGE + DETA, N-MPGE + TETA. N$\mathrm{MPGE}+\mathrm{AEP}$ and N-MPGE + IPDA) are represented in Figure

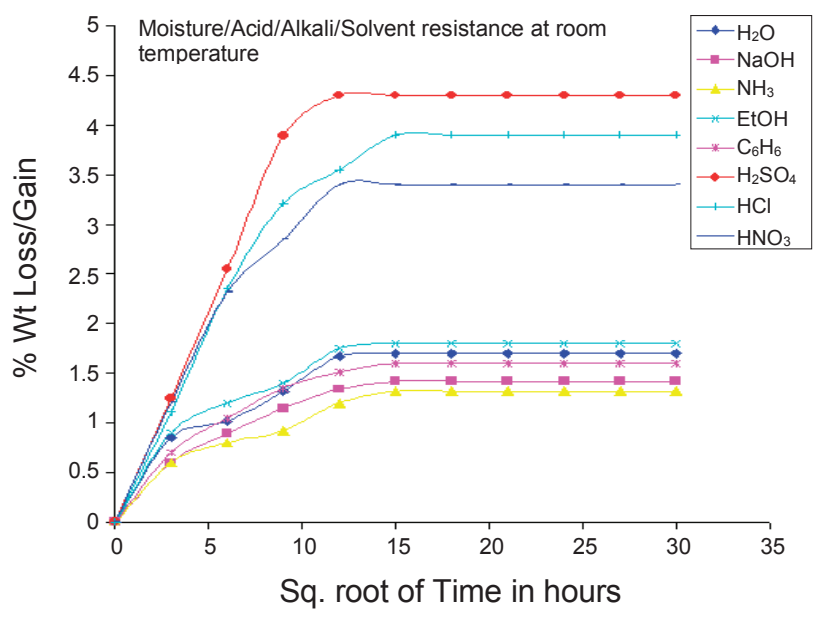

Figure 7. Chemical/moisture absorption resistance of N-MPGE with EDA at room temperature.

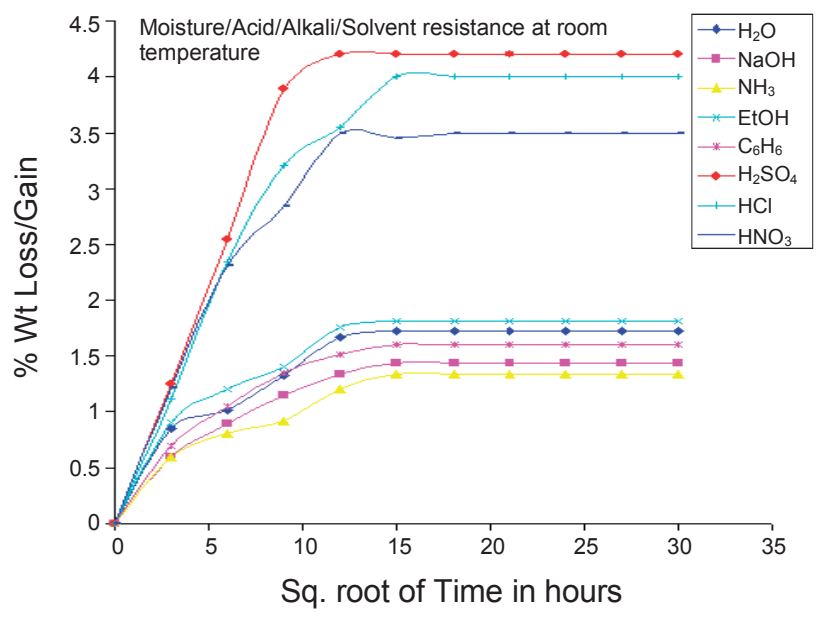

Figure 8. Chemical/moisture absorption resistance of N-MPGE with DETA at room temperature.

4. The dynamic scans were performed at a heating rate of 10 ${ }^{\circ} \mathrm{C} / \mathrm{min}$ and the data are summarized in Table 1 . From the figure it is clear that all the cured systems exhibit similar behaviour. The peak at 75 to $80{ }^{\circ} \mathrm{C}$ corresponds to the melting point of the cured epoxy systems. The peak at around 300 to $315^{\circ} \mathrm{C}$ is attributed to the exothermic curing reactions of the above mentioned epoxy and amines systems and the maximum of the exothermic peak obtained at $330-360{ }^{\circ} \mathrm{C}$. At about $400{ }^{\circ} \mathrm{C}$, the completion of curing process indicates the absence of exotherm peaks in the post cure in epoxy amine systems. Over all this indicates all five different N-MPGE with amines systems show the similar behaviors and also which conforms the homogeneity of the cured systems.

Thermal properties of the cured systems. The thermal stability of the maleimidophenyl resin was investigated with thermogravimetric analysis (TGA) in air atmosphere (see Figure 5). The thermograms of the cured maleimidophenyl glycidylether clearly indicate that the thermal stability of cured resins was improved with the incorporation of maleimide groups into the Epichlorohydrin molecule. ${ }^{16-18}$ With the incorporation of the 


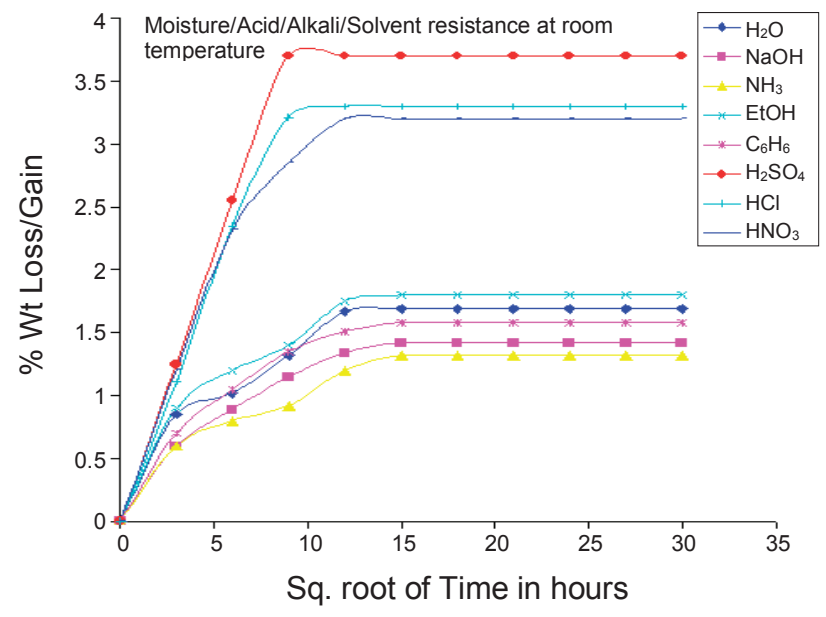

Figure 9. Chemical/moisture absorption resistance of N-MPGE with TETA at room temperature.

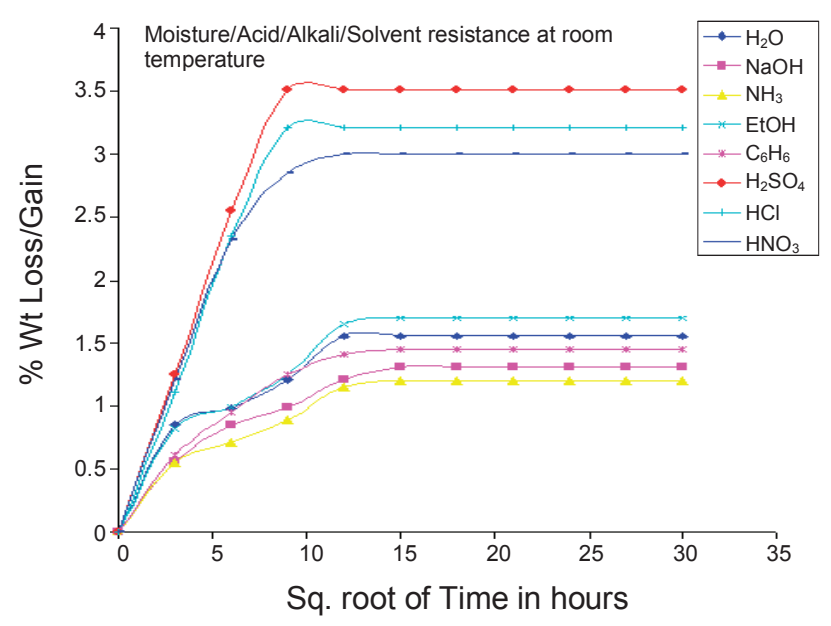

Figure 10. Chemical/moisture absorption resistance of N-MPGE with $\mathrm{AEP}$ at room temperature.

maleimide groups, the initial decomposition temperature (IDT) of the maleimidophenyl glycidylether epoxy resin was increased (see Table 1). The enhancement of the thermal stability due to incorporation of maleimide groups on maleimidophenyl glycidylether epoxy resins was thus demonstrated. On the other hand, the integral procedural decomposition temperature (IPDN) also systematically increased with incorporation of maleimide groups. The high IPDT indicates that the cured maleimidophenyl glycidyl epoxy compound with our chosen amines such as EDA, DETA, TETA, AEP, and IPDA shows good thermal stability.

Morphology studies of cured systems. The morphology of fracture surfaces of cured maleimidophenylglycidyl epoxy with amines (EDA, DETA, TETA, AEP, and IPDA) were examined using scanning electron microscope. All the above mentioned five systems exhibit similar morphology. From Figure 6 it is clearly seen that the fracture surfaces of the neat maleimidophenylglycidylether epoxy compound with amine exhibit a homogenous pattern. All the cured samples exhibit similar homogeneous network and show no formation of distinct domains,

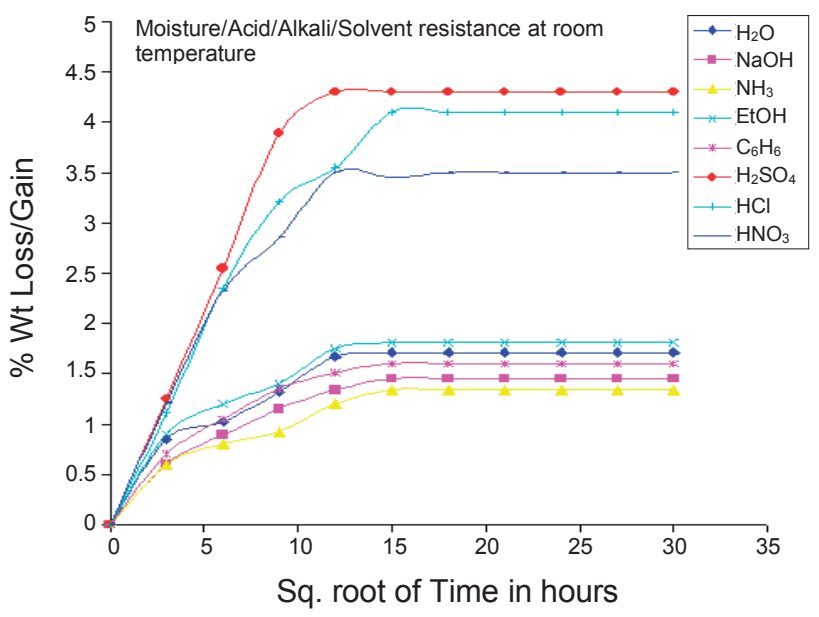

Figure 11. Chemical/moisture absorption resistance of N-MPGE with IPDA at room temperature.

confirming the formation of a homogeneous network in all the maleimidophenylglycidylether epoxy cured systems.

Moisture and chemical resistance measurements of cured systems. The chemical and water absorption curves of the cured N-MPGE + EDA, N-MPGE + DETA N-MPGE + TETA, NMPGE + AEP and N-MPGE + IPDA systems are shown in Figures 7-11. The goal of this study was to describe the interactions between the absorbed moisture and epoxy network. The transport of moisture through the epoxy network involves cooperative motion of water molecules and 3-dimensional resin network. The equilibrium water absorption of both systems was almost $1.71 \%$ by weight. One of the major factors affecting water absorption is the presence or absence of hydrophilic groups in the cross-linked network. There are same types of hydrophilic groups in the present systems. There are also other relevant factors to consider, notably free volumes, which generally increases with cross-link density because of the development of a rigid macromolecular framework. As shown in Figures 7-11 initially there is a sharp increase in water absorption due to water penetration into structural defects and cavities on the surface of samples. After some time $(120 \mathrm{~h})$ a slow process of water absorption reaches its equilibrium value of $1.71 \%$ at room temperature.

In the case of chemical resistance measurements the cured systems are studied with ammonia (as seen in Figures 7-11). Same trends in weight reduction are observed for all the systems. Initially the weight reduction is faster possibly due to washing some of the unreacted epoxy from surface of the samples. The second step is a slow weight reduction which can be due to washing some of the unreacted epoxy out of the bulk of the samples. The more complex the network is, the longer it takes for ammonia to diffuse into the system to reach to equilibrium. The weight reduction in ammonia reached to its equilibrium value of about $1.34 \%$ after $120 \mathrm{~h}$ immersion. The acid resistance of the cured systems was tested in the concentrated $\mathrm{H}_{2} \mathrm{SO}_{4}$, $\mathrm{HNO}_{3}, \mathrm{HCl}$. In these cases, all the cured systems show similar trend and the almost same weight reduction magnitude. As it is seen in Figures 7-10, there is almost a total of $4-4.3 \%$ weight loss which can probably be related to epoxy resins that are not contributed in the network formation. This can be due to the 
Table 3. The maximum moisture/acid/alkali/solvent resistance content under a given condition of temperature $\left(25^{\circ} \mathrm{C}\right)$

\begin{tabular}{|c|c|c|c|c|c|c|c|c|c|}
\hline \multirow{2}{*}{ Sl. No } & \multirow{2}{*}{ System } & \multicolumn{5}{|c|}{$\%$ Weight Gain } & \multicolumn{3}{|c|}{$\%$ Weight loss } \\
\hline & & $\mathrm{H}_{2} \mathrm{O}$ & $10 \% \mathrm{NaOH}$ & $\mathrm{NH}_{3}$ & $\mathrm{C}_{2} \mathrm{H}_{5} \mathrm{OH}$ & $\mathrm{C}_{6} \mathrm{H}_{6}$ & $\mathrm{H}_{2} \mathrm{SO}_{4}$ & $\mathrm{HCl}$ & $\mathrm{HNO}_{3}$ \\
\hline 1 & N-MPGE+EDA & 1.66 & 1.41 & 1.32 & 1.75 & 1.5 & 3.60 & 3.25 & 3.90 \\
\hline 2 & N-MPGE+DETA & 1.69 & 1.42 & 1.32 & 1.85 & 1.58 & 3.70 & 3.30 & 3.20 \\
\hline 3 & N-MPGE+TETA & 1.7 & 1.42 & 1.32 & 1.85 & 1.6 & 4.30 & 3.90 & 3.40 \\
\hline 4 & N-MPGE+AEP & 1.50 & 1.31 & 1.25 & 1.81 & 1.41 & 4.20 & 3.00 & 3.50 \\
\hline 5 & N-MPGE+IPDA & 1.71 & 1.45 & 1.34 & 1.81 & 1.6 & 4.30 & 4.10 & 3.50 \\
\hline
\end{tabular}

fact that in the present study we used low concentration of amines as curing agent was used.

The plots of moisture absorption $v s$. square root of time were constructed (Figures 7-11) to note the saturation limits of the absorbed moisture. From the figures it is observed that initially the water uptake increases, and showed a flat profile exhibiting Fickean type behavior. ${ }^{11}$ The maximum moisture absorbed under a given condition of temperature and humidity in case of maleimidophenylglycidyl epoxy compound with the amines showed a decreasing trend. The cured samples were found to have good chemical resistance (acid/alkali/solvent) and water absorption resistance as compared to traditional epoxy amine cured systems. ${ }^{19}$ This may be because of the incorporation of maleimide groups into the epichlorohydrin, which provides a cyclic imide structure and high cross-linking density to the cured resins.

The maximum moisture/acid/alkali/solvent resistance contents under a given condition of temperature in case of maleimidophenyl glycidylether epoxy compound with our amines systems are shown in the Table 3 . These data clearly indicate that the cured maleimidophenyl glycidylether epoxy compound with the curing agents (EDA, DETA, TETA, AEP, and IPDA) showed more resistance to water absorption and other chemicals. The AEP cured system exhibited slightly high resistant towards moisture/acid/alkali/solvent absorption than other amine cured systems. This may be due to this can possibly be credited to the presence of tertiary nitrogen ${ }^{19}$ (acts as catalyst), which accelerates the curing rate very much, resulting in the high cross-link density network when compared to other amines.

\section{Conclusions}

Phenylmaleimido group is successfully incorporated into epichlorohydrin and the resulting on a compound with both oxirane ring and maleimido reactive groups. The cured resins are obtained by thermal curing of the maleimidophenyl glycidylether epoxy compound with amines (EDA, DETA, TETA, AEP, and IPDA). Amines act as very good curing agents in the case of maleimidophenyl glycidyl ether epoxy compound. The higher reactivity in the case of AEP can be explained on the basis of tertiary amine group acting as a catalyst along with the primary and secondary amine groups present in it. The cured samples exhibited good thermal stability and excellent chemical (acid/alkali/solvent) and water absorption resistance. Morphological studies by the SEM technique further confirmed (confirm) the phase homogeneity network of the cured systems.

\section{References}

1. Jones, R. R., Ellis, B., Eds.; Chemistry and Technology of Epoxy Resins; London, Chapman and Hall: 1993; p 256.

2. Hay, J. N.; Woodfine, B.; Davies, M. High Perporm Polym. 1996, 8,35 .

3. Ishikawa, S.; Nakatani, M.; Fukuda, H.; Yamamoto, S. Jpn Patent 1996, 8, 253.

4. Agag, T.; Takeichi, T. Polymer 1999, 40, 6557.

5. Gaw, K.; Kikei, M.; Kakimoto, M.; Imai, Y. Polymer 1997, 38, 4413.

6. Kim, W. G.; Nam, T. Y. J. Polym. Sci. Part A: Polym. Chem. 1996, 34, 957

7. Park, S. J.; Kim, H. C.; Lee, H. I.; Suh, D. H. Macromolecules 2001, 43, 693.

8. Kumar, A. A.; Alagar, M.; Rao, RMVGK. Polymer 2002, 43, 693.

9. Musto, P.; Martuscelli, E.; Ragosta, G.; Scarinzi, G. J. Appl. Polm. Sci. 1998, 69, 1029.

10. Kumar, A. A.; Alagar, M.; Rao, RMVGK. J. Appl. Polym. Sci. 2001, 81, 2330.

11. Kumar, A. A.; Alagar, M.; Rao, RMVGK. J. Appl. Polym. Sci. 2001, 81, 38 .

12. Han, J. L.; Chen, Y. C.; Li, K. Y.; Hsieh, K. H. J. Appl. Polym. Sci. 1998, 70, 529.

13. White, L. A.; Weber, W. J.; Mathias, L. J. Polym. Bull. 2001, 46, 463.

14. Shibora, T.; Okuse, S.; Aoki, T.; Kato, H. US Patent 2000, 6, 143.

15. Vanaja, A. Ph. D Thesis, Bangalore University, Bangalore, 2003.

16. Chuan-S, Wu.; Ying-Ling, Liu.; Keh-Ying, Hsu. Polymer 2003, $44,565$.

17. Ashcroft, W. R., Ellies, B., Eds.; Chemistry and Technology of Epoxy Resin; London, Chapman and Hall: 1993; p 37.

18. Liu, Y. L.; Jeng, R. J.; Chiu, Y. S. J. Polym. Sci. Part A: Polym. Chem. 2001, 39, 1716.

19. Shivananda, K. N.; Mahendra, K. N. Int. Cong. of Chem. and Envi. 2005, 337.

20. Gun-S, Lee.; Young-C, Lee. Myoung-S, G. Bull. Korean Chem. Soc. 2001, 22, 1393.

21. Shivananda, K. N.; Mahendra, K. N. Ira. Poly. Jou. 2007, 16(3), 161-171.

22. Shivananda, K. N.; Mahendra, K. N. Bull. Korean Chem. Soc. 2006, 27, 10.

23. Shivananda, K. N.; Jagadeesh, R.V.; Mahendra, K. N. Journal of Molecular Catalysis A Chemical. 2006, 255.

24. Wu, S.; Liu, Y. L.; Chiu, Y. C.; Chiu, Y. S. Polym. Degrad. Stab. 2002, 41.

25. Wang, C. S.; Shieh, J. Y. Polymer 1998, 39, 4547-4556.

26. Liu, Y, L.; Liu, Y, L.; Chiu, Y. S. J. Polym. Sci. Part A: Polym. Chem. 2001, 56, 7617.

27. Liu, Y. L.; Hsiue, G. H.; Chiu, Y. S.; Jeng, R. J. J. Appl. Polym. Sci. 1996, 24, 957. 